Journal of Patient-Centered

4-19-2021

\title{
Preprocedure COVID-19 Testing in Early Phase of Pandemic
}

\author{
Renuka Jain \\ Bradley Kruger \\ Robert Citronberg \\ Stacie Kroboth \\ Ana Cristina Perez Moreno \\ Bijoy K. Khandheria
}

Follow this and additional works at: https://aah.org/jpcrr

Part of the Cardiology Commons, Epidemiology Commons, Health and Medical Administration

Commons, Infectious Disease Commons, Other Analytical, Diagnostic and Therapeutic Techniques and

Equipment Commons, Patient Safety Commons, Surgery Commons, and the Virus Diseases Commons

\section{Recommended Citation}

Jain R, Kruger B, Citronberg R, Kroboth S, Perez Moreno AC, Khandheria BK. Preprocedure COVID-19

testing in early phase of pandemic. J Patient Cent Res Rev. 2021;8:151-3. doi: 10.17294/2330-0698.1841

Published quarterly by Midwest-based health system Advocate Aurora Health and indexed in PubMed Central, the Journal of Patient-Centered Research and Reviews (JPCRR) is an open access, peer-reviewed medical journal focused on disseminating scholarly works devoted to improving patient-centered care practices, health outcomes, and the patient experience. 


\title{
Preprocedure COVID-19 Testing in Early Phase of Pandemic
}

\author{
Renuka Jain, MD, ${ }^{1}$ Bradley Kruger, MAEd, MBA, ${ }^{2}$ Robert Citronberg, MD, ${ }^{3}$ Stacie Kroboth, BS, ${ }^{4}$ \\ Ana Cristina Perez Moreno, MD, PhD, ${ }^{4}$ Bijoy K. Khandheria, MD ${ }^{1}$ \\ ${ }^{1}$ Aurora Cardiovascular and Thoracic Services, Aurora Sinai/Aurora St. Luke's Medical Centers, University of \\ Wisconsin School of Medicine and Public Health; ${ }^{2}$ Advocate Aurora Health, Milwaukee, Wl; ${ }^{3}$ nfectious Disease, \\ Advocate Aurora Health, Downers Grove, IL; ${ }^{4}$ Advocate Aurora Research Institute, Milwaukee, WI
}

Purpose

The COVID-19 pandemic led to a nationwide shutdown of elective medical procedures. Upon resumption of services, preprocedure nasopharyngeal swab testing for severe acute respiratory syndrome coronavirus 2 (SARS-CoV-2) was introduced for all patients requiring surgical or other aerosol-generating procedures. We investigated preprocedure COVID-19 testing in one of the largest U.S. health systems. Patients included in this retrospective, observational study were asymptomatic and scheduled for a procedure or surgery. All patients underwent a nasopharyngeal swab test for SARS-CoV-2 performed 24-72 hours prior to a planned procedure. Clinical demographics, type of procedure, test results, and subsequent procedure status were evaluated. Of 38,608 total patients, there were 277 COVID-19-positive patients (positivity rate: $0.72 \%$ ). Of those 277,244 (88\%) had procedural delays or cancellations. Of the COVID-19-negative patients, $50(0.13 \%)$ required later hospitalization for COVID-19. Median time from preprocedure negative test to admission was $46.3 \pm$ 27.2 days. In the largest series published on preprocedure COVID-19 testing in the early phase of the pandemic, preprocedure COVID-19 positivity was low. Preprocedure COVID-19 testing had a significant impact on clinical management. Rate of COVID-19 cases requiring hospitalization in the months following the procedure was negligible, suggesting health system policies adequately protected patient safety. (J Patient Cent Res Rev. 2021;8:151-153.)

Keywords SARS-CoV-2 testing; COVID-19; procedure; surgery; hospitalization; patient safety; health care delivery; clinical management

$\longrightarrow$ oronavirus disease 2019 (COVID-19) is caused by the severe acute respiratory syndrome coronavirus (SARS-CoV-2) pathogen. Early phases of the COVID-19 pandemic led to an unprecedented shutdown of elective medical procedures and surgeries (hereinafter referred to collectively as "procedures") to preserve bed availability, health care resources, staffing, and personal protective equipment. ${ }^{1,2}$ At Midwestern-based Advocate Aurora Health, one of the 12 largest integrated health systems in the United States with 500 clinical sites and 27 hospitals, a unified approach for resuming procedures was developed, which included preprocedure COVID-19 testing for presence of SARS-CoV-2.

This paper summarizes the health system's initial experience conducting this preprocedure testing.

Corresponding author: Bijoy K. Khandheria, MD, Aurora St. Luke's Medical Center, 2801 W. KK River Parkway, \#880, Milwaukee, WI 53215 (wi.publishing22@aah.org)

\section{METHODS}

At Advocate Aurora Health, elective outpatient procedures were suspended systemwide on March 16, 2020, and resumed on April 30, 2020. Upon resumption of procedures, screening was standardized. An order was placed for any patient with a planned procedure to have a nasopharyngeal swab molecular test for SARSCoV-2 performed 24-72 hours prior to procedure at any of 23 collection sites, with self-quarantine until the day of the prescribed procedure. Nearly all molecular test results $(98.9 \%)$ were obtained by a transcript-mediated, amplification-based method for detection of SARSCoV-2, utilizing the Aptima ${ }^{\circledR}$ assay (Hologic, Inc.).

At the time of the test, any patient with clinical concern for COVID-19 was redirected to a primary care provider for further management and was not included in this study. Inpatients requiring procedures were not included in this study. Clinical characteristics, all results of preprocedure testing, and subsequent hospitalizations postprocedure were collected via the health system's electronic medical records (Epic Systems Corporation and Cerner Corporation). Procedures were classified as 
Table 1. Frequency of Positive SAR-CoV-2 Testing Results Prior to a Scheduled Medical Procedure/Surgery by Clinical Specialty

\begin{tabular}{|c|c|c|c|c|}
\hline Clinical Specialty & $\begin{array}{l}\text { Test-Positive } \\
\text { Patients }\end{array}$ & $\begin{array}{l}\text { Procedure } \\
\text { Completed }\end{array}$ & $\begin{array}{c}\text { Procedure } \\
\text { Delayed }\end{array}$ & $\begin{array}{c}\text { Procedure } \\
\text { Canceled }\end{array}$ \\
\hline Cardiovascular & $38(13.7)$ & $5(13.2)$ & $23(60.5)$ & $10(26.3)$ \\
\hline Otolaryngology & $16(5.8)$ & $2(12.5)$ & $10(62.5)$ & $4(25.0)$ \\
\hline Ophthalmology & $8(2.9)$ & $1(12.5)$ & $6(75.0)$ & $1(12.5)$ \\
\hline Gastroenterology & $65(23.5)$ & $4(6.2)$ & $40(61.5)$ & $21(32.3)$ \\
\hline Hematology/Oncology & $10(3.6)$ & $2(20.0)$ & $8(80.0)$ & $0(0)$ \\
\hline Neurology/Pain & $11(4.0)$ & $9(9.1)$ & $7(63.4)$ & $3(27.3)$ \\
\hline Obstetrics/Gynecology & $29(10.5)$ & $11(37.9)$ & $17(58.6)$ & $1(3.5)$ \\
\hline Pulmonary & $21(7.6)$ & $2(9.5)$ & $12(57.1)$ & 7 (33.3) \\
\hline Other surgery & $79(28.5)$ & $5(6.3)$ & $63(79.8)$ & $11(13.9)$ \\
\hline All AGP & $241(87.0)$ & $24(10.0)$ & $162(67.2)$ & $55(22.8)$ \\
\hline All non-AGP & $36(13.0)$ & $9(25.0)$ & $24(66.7)$ & $3(8.3)$ \\
\hline
\end{tabular}

Data presented as $n$ (\%). Clinical specialty rows include both AGP-type and non-AGP-type scheduled procedures.

AGP, aerosol-generating procedures.

aerosol-generating procedures $(\mathrm{AGP})^{3}$ or non-AGP and further classified by specialty.

Categorical data were compared by performing Pearson's chi-squared test, and continuous data were compared by running a nonpaired $t$-test. A P-value of $<0.05$ was considered statistically significant. All analyses were performed using Stata ${ }^{\circledR} 15$ software (StataCorp LLC).

\section{RESULTS}

During the study period (April 30, 2020-July 7, 2020), 38,608 total preprocedure tests were ordered for outpatients throughout the health system, across multiple specialties (Table 1). All patients who had a negative SARS-CoV-2 test proceeded with the procedure.

The overall positivity rate for SARS-CoV-2 test in outpatient preprocedure testing was $0.72 \% \quad(n=277)$. Patients testing positive for SARS-CoV-2 were younger (mean age \pm standard deviation: $49.1 \pm 18.7$ years vs 56.5 \pm 18.5 years, respectively; $\mathrm{P}<0.001)$ and more likely to be African American (59 [21.3\%] positive vs 3854 [10.1\%] negative; $\mathrm{P}<0.001$ ). Given the population positivity and test characteristics during the time period, the falsenegative rate was estimated to be $6.5 \%$ and the falsepositive rate negligible (ie, $<1 \%$ ).

A positive preprocedure SARS-CoV-2 test altered management in the majority ( $88 \%$ ) of patients (Table 2 ). Of the 277 who tested positive, $36(13.0 \%)$ had a planned non-AGP, of which $24(66.7 \%)$ were delayed and 3 $(8.3 \%)$ were canceled without a plan to reschedule. Of the 241 positive patients with a scheduled AGP, only 24
Table 2. Frequency of Procedure Outcomes in 277 Patients Testing Positive for SARS-CoV-2

\begin{tabular}{lc}
\hline Procedure Outcome & $\mathbf{n}(\%)$ \\
\hline Completed & $33(11.9)$ \\
Delayed & $186(67.2)$ \\
Canceled & $58(20.9)$ \\
\hline
\end{tabular}

procedures were completed, 8 of which were in pregnant women scheduled for delivery. As a result of preprocedure testing positivity, the majority of these AGP were delayed $(n=162,67.2 \%)$ or canceled $(n=55,22.8 \%)$.

Of the patients who tested negative for SARS-CoV-2 and underwent a procedure, $50(0.13 \%)$ required later hospitalization for COVID-19. The mean time from preprocedure negative test to admission was $46.3 \pm$ 27.2 days. Only 10 patients were hospitalized with COVID-19 within 14-21 days after the procedure, and none of these hospitalizations were documented to be associated with the procedure.

\section{DISCUSSION}

In one of the largest series published on preprocedure COVID-19 testing in the early phase of the pandemic, preprocedure COVID-19 positivity was low $(0.72 \%)$; however, preprocedure COVID-19 testing had a substantial impact on clinical management. The rate of COVID-19 requiring hospitalization postprocedure was negligible, suggesting health system policies successfully guarded patient safety. 
Preprocedure testing was part of a system strategy for resumption of procedures. Goals were to 1) provide appropriate medical care, 2) preserve health care resources, and 3) limit virus exposure to staff and patients. Universal masking and temperature checks already had been implemented for all by mid-April 2020 . Another key tool included modernization of ventilation systems. Decisions about type and pace of resumption of procedures were left to individual physician discretion in conjunction with clinical leadership. Unless deemed clinically necessary, procedures were postponed for patients who tested positive for SARS-CoV-2; this was based on surgical data demonstrating worse morbidity and mortality in patients with perioperative COVID-19.,5 Our results were similar to another study performed within a large health system that tested algorithms that included level of risk and elective/urgency of procedure in determining preprocedure testing, ${ }^{6}$ the difference in methods being that our study examined all patients under consideration for procedure regardless of urgency.

One limitation of the database queried is that we did not have information available on COVID-19 positivity rates of the health care providers taking care of these patients or on costs associated with procedural delays/cancellations. Although further research is required to evaluate the cost-effectiveness and clinical utility of preprocedural testing, this report should reassure patients and physicians about the low prevalence of preprocedural COVID-19 in communities in which overall positivity rates are low.

\section{Patient-Friendly Recap}

- In an attempt to safely resume performing elective surgeries during the COVID-19 pandemic, one large health system enacted a preprocedure SARS-CoV-2 testing protocol.

- Authors found that a mere $0.72 \%$ of more than 38,000 patients tested positive for SARS-CoV-2 prior to their scheduled procedure; nearly $90 \%$ of patients who did test positive had their procedures delayed or canceled.

- This protocol appeared to have sufficiently protected patients and health care providers from contracting COVID-19 while participating in medical procedures.

\section{Author Contributions}

Study design: Jain, Kruger, Citronberg, Khandheria. Data acquisition or analysis: Jain, Kroboth, Perez Moreno. Manuscript drafting: all authors. Critical revision: all authors.

\section{Conflicts of Interest}

None.

\section{References}

1. Centers for Medicare \& Medicaid Services. Non-emergent, elective medical services, and treatment recommendations. Published April 7, 2020; accessed November 10, 2020. https:// www.cms.gov/files/document/cms-non-emergent-electivemedical-recommendations.pdf

2. Wang J, Vahid S, Eberg M, et al. Clearing the surgical backlog caused by COVID-19 in Ontario: a time series modelling study. CMAJ. 2020;192:E1347-56. CrossRef

3. Tran K, Cimon K, Severn M, Pessoa-Silva CL, Conly J. Aerosol generating procedures and risk of transmission of acute respiratory infections to healthcare workers: a systematic review. PLoS One. 2012;7(4):e35797. CrossRef

4. Dowlati E, Zhou T, Sarpong K, et al. Case volumes and perioperative coronavirus disease 2019 incidence in neurosurgical patients during a pandemic: experiences at two tertiary care centers in Washington, DC. World Neurosurg. 2020;143:e550-60. CrossRef

5. Nahshon C, Bitterman A, Haddad R, Hazzan D, Lavie O. Hazardous postoperative outcomes of unexpected COVID-19 infected patients: a call for global consideration of sampling all asymptomatic patients before surgical treatment. World J Surg. 2020;44:2477-81. CrossRef

6. Schlosser M, Signorelli H, Gregg W, Korwek K, Sands K. COVID-19 testing processes and patient protections for resumption of elective surgery. Am J Surg. 2021;221:49-52. $\underline{\text { CrossRef }}$

(C) 2021 Advocate Aurora Health, Inc. 